\title{
Psikolojik Danışma ve Psikoterapide Bütünleşmeye Doğru
}

\author{
DOI: 10.26466/opus.688166
}

\author{
Meliha Tuzgöl Dost * \\ * Doç. Dr. Hacettepe Üniversitesi, Eğitim Fakültesi, Ankara / Türkiye \\ E-Posta: mtuzgoldost@gmail.com \\ ORCID: 0000-0001-7852-6633
}

\begin{abstract}
Öz
Insanlık tarihinde her toplumda ruhsal sıkıntıları hafifletme görevi üstlenen kişiler olmuştur ancak bu eylemin resmen psikoterapistlere ait olması yaklaşık olarak yüz yıl öncesine dayanır. Zaman içerisinde pek çok psikolojik danışma ve psikoterapi kuramı ortaya çıkmıştır. Günümüzde ise 400'ün üzerinde psikoterapi sistemi olduğu bilinmekte ve her geçen gün bu sayı artmaktadır. Psikoterapilerin sayısının artışı, bütün danışan ve sorunlara tek bir kuramla yaklaşmanın yetersiz kalması ve terapötik ortak etkenlerin terapi sonucuna önemli katkılar olduğunun fark edilmesi gibi nedenlerle son dönemde psikoterapi kuramları arasındaki benzerlikleri bulma ve bütünleşmeye gitme anlayışı hız kazanmıştır. Psikoterapilerin bütünleşmesi ile ilgili pek çok yol bulunmaktadır. Bütünleşmede en popüler dört yol teknik eklektisizm, kuramsal bütünleşme, ortak faktörler ve özümseyici bütünleşmedir. Teknik eklektisizm, belli bir kurama bağlı kalmaksızın farklı yaklaşımların tekniklerini kullanmayı içerir. Kuramsal bütünleşme, iki veya daha fazla psikoterapi kuram ve tekniklerini yeni bir kavramsallaştırma veya terapi yaklaşımına dönüştürmek üzere bütünleştirmektir. Ortak faktörler yaklaşımı, farklı terapilerin paylaştığı temel bileşenleri belirlemeyi ve ortaklıklarına dayanarak daha etkili terapiler yaratmayı hedeflemektedir. Özümseyici bütünleşme ise, diğer yönelimlerin teknik ve ilkelerini bütünleştirirken temel bir kuramsal oryantasyona bağlı kalmayı tercih eder. Bütünleşme çabaları psikoterapide ortak bir dil oluşturma, bölünme ve parçalanmanın önüne geçme, yeni marka isimleri yaratmaktansa psikoterapide etkililiği ön plana alma açısından önem arz etmektedir. Bu arada, bütünleşme çabalarının yeni psikoterapi formlar üretmesi istenmeyen bir sonuçtur. Bütünleşme çabalarının esas amacının farklllıklar içindeki benzerliği bulmak olduğu unutulmamalıdır.
\end{abstract}

Anahtar Kelimeler: Psikolojik danışma, psikoterapi, psikolojik danışma kuramları, psikoterapi kuramları, bütünleşme 


\title{
Towards Integration in Psychological Counseling and Psychotherapy
}

\begin{abstract}
Throughout the history of humanity, there have always been people in societies who took on the role of disburdening peoples' emotional distress; however, the psychotherapists officially taking over this role dates back approximately a hundred years. In time, various psychological counseling and psychotherapy theories have come about. Today, it is known that there are over 400 psychotherapy systems, and this number increases as days go by. Due to various reasons such as the increase in the number of psychotherapies, the inefficiency of approaching all clients and problems with a single theory, and the realization that therapeutic common factors have important contribution to the end result of therapy accelerated the efforts of integration and trying to find similarities between psychotherapy theories. There are many ways to integrate psychotherapies. The four most popular ways in integration are technical eclecticism, theoretical integration, common factors, and assimilative integration. Technical integration denotes using techniques from different approaches without depending on a certain theory. Theoretical integration means integrating two or more psychotherapy theories and techniques in order to turn them into a new conceptualization or therapy approach. Common factors approach aims to determine the common components shared by different therapies and to create more effective therapies based on this commonality. Assimilative integration, on the other hand, prefers to stick to one basic theoretical orientation while integrating the techniques and principles of other inclinations. Integration efforts are significant in terms of creating a common language in psychotherapy, preventing division and disintegration, and prioritizing effectiveness rather than creating new brand names in psychotherapy. Meanwhile, integration efforts creating new psychotherapy forms is an undesirable outcome. It should not be forgotten that the main aim of integration efforts is to find out similarities within differences.
\end{abstract}

Keywords: Psychological counseling, psychotherapy, counseling theories, psychotherapy theories, integration 


\section{Giriş}

“Bütünleşme, yöntemlerdeki farklllkkların mekanik birleşimini oluşturmak değil farklılık içinde neyin benzer olduğunu aramaktır."

V. E. Kegan

İnsan davranışları, ruhsal yapısı, kişilik gelişimi, duygu, düşünce ve davranışları ile bunların nedenleri, sonuçları, ruhsal sorunlar ve çözümleriyle ilgilenen psikoloji alanı nispeten genç bir bilim dalıdır. İnsanı anlama yolculuğu, insanoğlu var olduğundan beri hep olmuş olmakla birlikte bu çabanın farklı bir disiplin olarak ele alınmasının tarihi çok yakın geçmişe dayanır. Bu genç bilim dalı bir yandan insan davranışlarının nedenlerini anlamaya çalışırken, bir yandan da ruhsal sorunların nasıl tedavi edilebileceğine yönelik yöntemler geliştirmeye çalışmıştır. Günümüzde hem psikolojik danışma hem psikoterapi insanı mutsuz eden, uyumsuz ve işlevsiz kılan davranışların nasıl değiştirilebileceğine yönelik ilke, yöntem ve süreçler üzerinde çalışmaktadır. Oldukça takdire değer bir yol alınmış olsa da söz konusu olan insanın karmaşıklığı olduğundan, daha alınacak epey yol var gibi görünmektedir. Al1nacak yollardan biri de psikoterapi ve psikolojik danışma kuramlarındaki bütünleşme çabalarıyla ilgilidir. Bu çalışmada psikoterapi ve psikolojik danışma alanındaki bütünleşme hareketinin başlangıcı, gelişimi ve geldiği durum ele alınmaya çalışılmıştır. Bu amaçla, dünyada konu üzerinde yıllardır çalışan önder bilim insanlarının kitap, kitap bölümü ve makaleleri incelenmiş; bütünleşme çabalarıyla ilgili genel bir çerçeve oluşturacak bir derleme yazısı hazırlamak hedeflenmiştir.

İnsanın işlevsel olmayan, sağlıksız davranışlarının nasıl değiştirilebileceğine yönelik olarak psikolojik danışma ve psikoterapide pek çok kuram geliştirilmiştir. Murdock'a (2012, s.2) göre, geleneksel olarak, psikoterapinin "kişilik değişimi" ve "derinlemesine çalışma" ile ilgili olduğu, psikolojik danışmanın ise daha kısa süreli, problemin çözümüne odaklı ve daha az yoğunlukta olduğu düşünülür. Yine Murdock'a (2012) göre günümüzde pek çok kişi psikolojik danışma ve psikoterapi arasında böyle bir ayrım yapmamakta; aradaki farkın daha çok kişinin ideolojisiyle ilgili olduğu düşünülmektedir. 
Bu nedenle yazar kitabında "psikolojik danışma ve psikoterapiyi" ve "psikolojik danışman, psikoterapist ve terapisti" dönüşümlü olarak kullanmayı tercih ettiğini belirtir.

Daha derin ve daha klinik sorunların ele alındığı ve süreç sonunda kişilik değişiminin amaçlandığı ilişkiye psikoterapi; daha kısa süreli, problem odaklı ve gelişimsel sorunlarla ilgilenen alanın psikolojik danışma olduğunu kabul etmek durumunda dahi, her iki süreçte de amaç, konuşarak insanların ruhsal sorunlarını çözmelerine, daha verimli ve mutlu bireyler olmalarına yardımcı olmaktır. Danışanlar kendini tanıma, sorunlarını çözme, daha işlevsel, daha anlamlı bir yaşam sürebilme, gelişimsel krizleri sağlıklı bir şekilde aşma, kişiler arası ilişkilerde yaşanan sorunlar, mesleki, eğitsel ve çeşitli karar durumlarıyla ilgili çatışmalarla olsun; daha klinik bir tablo içerisinde, belli ruhsal hastalıkların tedavisi için başvurmuş olsun, psikolojik danışma ve psikoterapi süreçlerinin her ikisinde de kullanılan kuramsal temel, model ve teknikler benzerdir, hatta aynıdır. Bu durum alandaki birçok kitabın adının "psikolojik danışma ve psikoterapi kuramları" (Corey, 2015; Murdock, 2012; Sharf, 2014) olmasından da anlaşılmaktadır. Bu nedenle bu yazıda da "psikolojik danışma ve psikoterapi", "psikolojik danışman, psikoterapist ve terapist" kavramları birbirinin yerine kullanılacaktır.

Psikolojik danışma ve psikoterapi süreçlerinin anlamı ve işlevi konusunda da olduğu gibi, alanda pek çok sorunun tam bir yanıtının olmaması belki de psikoloji ve psikoterapi uzmanlığının görece kısa bir tarihe sahip olmasından kaynaklanmaktadır. İnsanlık tarihinde her toplumda ruhsal sıkıntıları hafifletme görevi üstlenen kişiler olmuştur ancak bu eylemin psikoterapistlere ait olması yaklaşık olarak yüz yıl öncesine dayanır (Stricker ve Gold, 2012). Bu süre içerisinde evrensel olarak kabul edilmiş tek bir psikoterapi tanımı yoktur. Bununla birlikte psikoterapi olarak adlandırılan herhangi bir etkinlik karşlıklı olarak kabul edilen hedefler çerçevesinde yalnızca "insanlara yardım etme amacı" ile yürütülmelidir (Prochaska ve Norcross, 2014).

Norcross ve Goldfried'a (2005) göre, Freud'un konuşma terapisini kullanmaya başlamasından günümüze kadar psikoterapi dünyası bölünme ve dogmatizm içinde olmuştur. Freud'un psikanalizinden sonra davranışçlık, bilişsel yaklaşım ve hümanist yaklaşımların temel kuramsal yaklaşımlar olduğu bilinmektedir. Günümüzde ise yüzlerce psikoterapi yaklaşımı olduğundan bahsedilmektedir. Psikoterapi model ve yaklaşımları her geçen gün artmaktadır. Bu yaklaşımların her biri birbirinden tamamen farklı söylemlerde mi 
bulunmakta; insanın davranışının nedenleri ve davranış değişiminin ilkelerine ilişkin tamamen farklı açıklamalar mı getirmektedir? Bu sayıda ve çeşitlilikte psikoterapi modeli olması bir yandan bir zenginlik ve insanı anlamaya çalışan psikoloji biliminin yolculuğunun kaçınılmaz bir sonucu olarak düşünülebilir ancak bazı yaklaşım ve modellerin bir öncekini tekrar etmesi, daha önce söylenmiş olanı farklı bir kavramla sunmasının ne kadar anlamlı olduğu tartışma konusudur.

Bu durumu Prochaska ve Norcross (2014), son 50 yll boyunca terapilerin markalaşma enflasyonuna tanık olunduğu şeklinde ifade etmektedir. Bu kapsamda Harper 1959 yılında 36 ayr1 psikoterapi sistemi tanımlarken; 1976'da Parloff 130'dan fazlasın keşfetmiş ve 1979 yılında Time Dergisi 200 'den fazla terapi modeli olduğunu yazmıştır. Günümüzde ise 400'ün üzerinde psikoterapi sistemi olduğu bilinmekte ve her geçen gün bu sayı artmaktadır. Gold'a (2002) göre ilk psikoterapi yaklaşımlarından günümüze dek, psikoterapi uygulayıcı ve öğrencileri kendi kuramları dışındaki sistemleri öğrenme konusunda son derece isteksiz davranmışlardır. Her psikoterapi okulu diğerlerinden soyut bir şekilde farklı bir ülkede gelişmiş; bu durum psikoterapi okulları arasında diğer kuramlarla ilgili olarak bilimsel bir değerlendirme ve sistematik bir çalışma yapmaksızın onları göz ardı etme gibi istenmeyen sonuçlar doğurmuştur. Bu nedenle uygulamacilar ve danışanlar yeni yaklaşımların getirdiği yeniliklerden yararlanma olanağı bulamamışlardir.

Her ne kadar durum buysa da son zamanlarda bu farklı akımlar arasındaki ortaklıkları görmeye çalışma çabaları başlamıştır. Yine de bütünleşmeye hala direnen bir anlayış da mevcuttur. Tracy'e (2018) göre, günümüzde iki farklı rakip anlayış bulunmaktadır. İlk anlayışa sahip olanlar psikoterapi paradigmaları arasında köprüler kurma ve bütünleşmeye gitme arayışı içindedir. İkinci anlayış ise farklı yaklaşımlar arasındaki sınırları katılaştırma eğilimindedir ve bütünleşmeye direnmektedir. İkinci eğilimin, kendi psikoterapi kuramlarının iyi işlediğini gösteren klinik araştırma sonuçları, bir kuramın kavram ve tekniklerinin karışmasının psikoterapide yetersiz sonuçlar doğuracağ1 düşüncesi ve akademik kültürdeki rekabet unsuru gibi nedenlere dayandığı düşünülmektedir. Diğer yandan öncelikli olarak sorulması gereken soru 400'ün üzerinde farklı terapi olup olmadığıdır. Gerçekten bu kadar farklı terapi türü var mıdır yoksa farklı psikoterapi modelleri kullanan bazı 
kuramcılar temelde aynı prensiplerle çalışırken bunları farklı terapötik dillerle mi ifade etmektedir? (Evans ve Gilbert, 2012). Psikoterapileri bütünleştirmeye olan ilgi artışının, farklı modeller arasında sanılandan daha fazla ortaklık olduğunun işareti olarak yorumlamanın mümkün olduğu düşünülmektedir.

Kontrollü sonuç çalışmaları ilginç bir şekilde farklı psikoterapi uygulamaları arasında küçük farklar olduğunu göstermektedir. Aktif terapilerin birbirleriyle karşılaştırıldığı meta analiz çalışmaları incelendiğinde küçük veya önemsiz etkiler görülmektedir (Luborsky vd., 2002). Luborsky, Singer ve Luborsky (1975) bu durumu Alice Harikalar Diyarında adlı masaldaki Dodo kuşunun hükmüne benzetirler. Alice Harikalar Diyarında adlı masalın bir sahnesinde, Dodo kuşu bir koşuda yarışanları değerlendirir ve «herkes kazandı, herkes ödül almalı diye hükmeder (Norcross ve Goldfried, 2005). Psikoterapi sonuç çalışmalarınn durumu da Dodo kuşunun hükmünden farklı değildir. Her nasılsa tüm terapiler kazanmaktadır.

Wampold (2001; Akt. Prochaska ve Norcross, 2014), yaptığı kapsamlı meta analiz çalışmalarını temele alarak, bazı psikoterapilerin daha iyi sonuçlar verdiği iddiasında olan araştırmaların en az üç açıdan yanıltıcı olduğunu savunmaktadır. İlk olarak, sıklıkla terapinin etkileri abartılı değerlendirilir; aslında olumlu etkinin temel nedeni daha çok terapisttir. Bazı terapistler diğerlerinden daha etkilidirler. İkinci olarak, terapi amacı güden bir terapi ile terapi bile olmayan bir süreç arasında karşılaştırma yapılabilmektedir. Diğer deyişle kimi zaman karşılaştırmalar yapısal olarak eş değer olmayan iki süreç arasında olmaktadır. Üçüncü neden ise araştırmacının kuramsal bağlılığının araştırma sonuçlarına olan etkisidir. Sonuç araştırmacıları büyük oranda geçerliliğini test ettikleri kuramların aktif temsilcisidirler. Bu durum araştırmadaki objektifliklerini etkileyebilmektedir.

Tüm bu kaygılardan dolayı terapiler arasında bütünleşmeye gidilmesi gerektiğini düşünenler bulunmaktadır. Bütünleşme dendiğinde ilk akla gelen kavramlardan biri de eklektisizm olmaktadır. Bütünleşme ve eklektisizm kavramları sıklıkla birbirinin yerine kullanılmakla birlikte bu kavramların arasında temel farklılıklar vardır. Eklektisizm bir seçme sürecidir; bir anlamda ayırma, koparıp alma işidir; oysa bütünleşme bir araya getirme sürecidir. Bütünleşme yeni bir bütün oluşturmaktır (Hollanders, 2009). Eklektisizm daha çok, farklı terapi yönelimlerinin potansiyel olarak etkili tekniklerini seçme pratiği olan teknik eklektizmden söz etmek için kullanılmaktadır. 
Bütünleştirme ise kuramsal ya da kavramsal bütünleştirmenin bazı biçimlerini ifade etmektedir (Wolfe ve Goldfried, 1988). Bütünleşme daha kapsamlı bir kavram olup, eklektisizm bütünleşme yollarından biridir. Dolayısıyla psikoterapide ortak bir dil oluşturma, farklı kuramların işaret ettiği benzer noktaları görme ve bağlantı kurma işini eklektisizm değil, bütünleşme kavramı daha iyi ifade etmektedir.

Bütünleşmenin nasıl olması gerektiğine ilişkin tek bir yol üzerinde anlaşılmış değildir. Farklı bütünleşme anlayışları ve yolları bulunmaktadır. Yazının bundan sonraki bölümlerinde sırasıyla bütünleşmenin kısa tarihçesi, bütünleşmenin gerekçelerine ilişkin düşünceler ve bütünleşme yolları / tarzları sunulacaktır. Bütünleşme tarzları verilirken her bir bütünleşme tarzına örnek teşkil eden bir veya birkaç kuram da kısaca tanıtılacaktır. Ardından, son olarak bütünleşme çabaları sürecinde dikkate alınması gereken önemli noktalara değinilecektir.

\section{Bütünleşmenin Tarihçesi}

Goldfried'a (1995a) göre bütünleşmenin tarihi 1932'de French'in yaptığ 1 çalışmaya kadar uzanır. French, Amerikan Psikoloji Derneği'nin 88. toplantısında psikanalizin kavramı olan bastırma ile davranışçılığın kavramı olan sönmenin benzer kavramlar olup olmadığını incelediği bir çalışma yapmıştır. French'in bu sorgulaması, farklı kavramlar kullanılmasına rağmen benzer süreçlerin ifade edildiğini dile getiren önemli bir çalışma olmuştur. Ardından 1936'da Rozenweig, kullanilan kuram ve kavramlardan ziyade terapistin kişiliğinin önemli bir etken olduğunu ve terapistlerin yorumlarıyla danışanlara farklı bakış açıları kazandırdıklarını dile getirmiştir (Goldfried, 1995b). Rosenzweig'in psikoterapi alanında artan yaklaşımlardaki ortak faktörlerle ilgili bu çalışması, bütünleşme alanının zenginleşmesini sağlayan çalışmalardan biri olmuştur.

Psikanaliz ve davranışçlık arasında köprü kurma niyeti taşıyan bir başka çalışma ise Dollard ve Miller'ın (1950) "Kişilik ve Psikoterapi" adlı kitabı olmuştur. Bu tip çalışmalar 1960'lı ve 70'li yıllarda çeşitli makale ve kitaplarla devam etmiş; bu makale ve kitaplarda çeşitli yöntemsel bütünleşme tanımları yapılmış ve öne sürülmüştür (Stricker ve Gold, 2012). Bu çalışmaları izleyen Paul Wachtel'in 1977'de «Psikanaliz ve Davranış Terapisi: Bir Bütünleşmeye Doğru» adlı çalışması önemli bir dönüm noktası olarak kabul edilmektedir. 
Bu kitap modern psikoterapi bütünleşme tarihinde en etkili ve çok başvurulan kitaplardan biri olmuştur. Ardından 1979'da James Prochaska, geniş bir kuramsal çerçeve yaratmaya yönelik ilk girişim olan psikoterapiye kuramlar ötesi bir yaklaşım önermiş ve 1979 'da, Marvin Goldfried, Paul Wachtel ve Hans Strupp, psikoterapide entegrasyon ile ilgilenen klinisyenler ve akademisyenler için Psikoterapide Bütünleşme Araştırmaları Derneği'ni (Society for the Exploration of Psychotherapy Integration (SEPI) kurmuşlardır (Prochaska ve Norcross, 2014). Ayrıca o zamanların bilinen en önemli bütüncül terapilerinin yer aldığı iki önemli el kitabı olan Psikoterapide Bütünleşme Elkitabı (Handbook of Psychotherapy Integration; Norcross ve Goldfried, 1992) ve Psikoterapide Bütünleşmenin Kapsamlı Elkitabı (Comprehensive Handbook of Psychotherapy Integration; Stricker ve Gold, 1993) 1990'ların başında yayınlanmıştır. Ardından 1982 yılında «The International Journal of Eclectic Psychotherapy» adlı dergi yayınlanmış; daha sonra adı «Journal of Integrative and Eclectic Psychotherapy» olarak değiştirilmiştir. Dergi, 1991'den itibaren, «Journal of Psychotherapy Integration» olarak yayınlanmaya başlamıştır. Bütünleşme çabaları ve bu çabaya yönelik yayınlar ilerleyen yıllarda devam etmiştir. Günümüzde de bütüncül yaklaşımların çeşitli sorun alanlarının terapisinde etkililiğinin ele alındığı araştırma ve yayınlar devam etmektedir.

\section{Bütünleşmenin Gerekçeleri}

Bütünleşme çabalarının son yıllarda daha fazla artmış olması bazı nedenlere bağlanmaktadır. Norcross (2005), bu artışın başlıca sekiz nedeni olduğunu belirtmektedir: Bunlar; 1. Terapilerin artış1; 2. Bütün danışan ve sorunlara tek bir kuramla yaklaşmanın yetersiz kalması; 3. Dış sosyo-ekonomik koşullar; 4 . Kısa süreli, çözüm odaklı terapilerin yükselişi; 5 . Terapistlerin özellikle zor sorunlarda çeşitli tedavileri gözlemleme olanakları; 6 . Terapötik ortak etkenlerin terapi sonucuna önemli katkıları olduğunun fark edilmesi; 7 . Belirli terapilerin etkilerinin tanımlanması ve kanıta dayalı terapiler ve 8 . Bütünleşme odaklı profesyonel bir örgütün gelişimidir.

Fernández-Álvarez, Consoli ve Gómez (2016) bütünleşmenin temel nedenlerini pratik, kuramsal ve bilimsel nedenler olarak ele almışlardır. Pratik nedenlerden ilki bütünleşmenin pek çok uygulayıcı tarafından onaylanmasıdır. Uygulamacılar tek bir psikoterapi formu kullanmaktansa temel psikote- 
rapi yaklaşımlarının çoğunu onaylama eğilimindedir. Psikoterapide bütünleşme için bir başka pratik neden de kendine özgü formdaki yaklaşımların çoğunun zamanla diğer yaklaşımlardan da stratejiler, müdahaleler ve teknikleri içermeye başlamasıdır. Kuramsal olarak ise psikoterapide çok fazla model olması psikoterapistler için kafa karışıklığına neden olan bir durumdur. Birçok uzman yüzlerce modelin aslında psikodinamik, bilişsel-davranışçı, varoluş̧̧u-insancl-yaşantısal ve sistemik olmak üzere dört temel kurama indirgenebileceği konusunda hem fikirdir. Bütünleşmenin bilimsel nedeni ise, konuyla ilgili gittikçe artan araştırmalar, üzerinde uzlaşma sağlanan kılavuzlar ve bazı önemli bilgiler sağlayan kararlar olmasıdır.

Bütüncül terapilerin hızlı artışında başka nedenlerin de rol oynamış olabileceği dile getirilmektedirler. Gold ve Stricker (2012) psikanaliz, davranış̧̧ terapi veya danışan odaklı terapi gibi psikoterapinin ayrı biçimlerinin köklerinin birkaç nesil öncesine dayandığını; bu ekollerin ilk kurucu ve takipçileri artık aramızda olmadıklarından yeni nesillerin, daha az ayrılıkçı olma ve sınırları aşma konusunda daha rahat ve kendinden emin davrandıklarını düşünmektedirler. Yeni nesil kuramcllar yeni bir terapötik yaklaşım yaratırken farklı ekollerden yararlanmakta bir sakınca görmemekte; bu da bütüncül psikoterapi modellerinin artmasını sağlamaktadır.

\section{Bütünleşme Yolları}

Psikoterapilerin bütünleşmesiyle ilgili pek çok yol bulunmaktadır. Bütünleşmede yaygin olarak bilinen dört yol ise 1. Teknik eklektisizm, 2. Kuramsal bütünleşme, 3. Ortak faktörler ve 4. Özümseyici bütünleşmedir. (Norcross ve Goldfried, 2005). Teknik eklektisizm, farklı kuramları birleştiren yeni bir kavramsal model yaratmaya çalışmaksızın farklı yaklaşımların tekniklerini kullanmayı içerir. Teorik / kuramsal bütünleşme ise, iki veya daha fazla psikoterapi kuram ve tekniklerini yeni bir kavramsallaştırma veya terapi yaklaşımına dönüştürmek üzere bütünleştirmektir. Ortak faktörler yaklaşımı, kuramların benzersiz olduğu iddiasının ötesine geçerek farklı terapötik yönelimler arasında paylaşılan bileşenlere ve ilkelere odaklanır. Son olarak, diğer üçünün aksine özümseyici bütünleşme diğer yönelimlerin teknik ve ilkelerini bütünleştirirken temel bir kuramsal oryantasyona bağlı kalmayı tercih eder (Castonguay vd., 2015, s. 4). Yaygın olan bu bütünleşme tarzlarına ve her bir tarza ait örnek kuramlara aşağıda yer verilmiştir. 


\section{Teknik Eklektisizm}

Teknik eklektisizm farklı danışan ve sorunlar için en iyi terapi yöntemlerini seçebilme becerisini geliştirme çabasıdır. Bu arayışa, geçmişte benzer sorunu olan ve benzer özelliklere sahip danışanlarda en çok hangi yöntemlerin işe yaradığına ilişkin araştırmalar ışık tutar (Norcross, 2015). Teknik eklektisizmi benimsemiş bir terapist belli sorunların çözümünde etkili olduğu kanıtlanan farklı kuramların tekniklerini kullanmakta özgür hisseder.

Arnold Lazarus'un çok boyutlu terapisi teknik seçmeciliğge bir örnektir. Lazarus, Güney Afrika'da doğmuş ve orada eğitim almıştır. Doktora hocası Joseph Wolpe'dir. Lazarus davranışçı yaklaşım kökeninden gelmektedir ancak psikoterapide davranışçı müdahaleleri yeterli görmemiştir. Lazarus, 1973 yılında «çok boyutlu terapi» diye adlandırdığı, tüm modaliteleri kapsamlı bir şekilde içine alan faklı bir yaklaşım ortaya koymuştur. Lazarus danışanın kişisel ihtiyaçlarının önemli olduğuna ve teknikleri buna göre seçmek ve uygulamak gerektiğine inanmaktadır (Prochaska ve Norcross, 2014). Lazarus'un (2013) özellikle eleştirdiği görüşlerden biri, Rogers'ın öne sürdüğü empati, mutabakat ve danışana olumlu gözle bakmanın gerçek bir kişilik değişimi için yeterli olduğu görüşüdür. Lazarus, bireysel ayrılıklar gerçeğine rağmen, her danışan için aynı müdahalenin yeterli olduğu ve herkesin aynı kalıptan çıktığı varsayımını anlayamamaktadır. O'na göre terapist “bukalemun terapist" olmalıdır. Danışman danışana en uygun ilişkiyi sunmak amacıyla terapötik ilişkideki kendi rolünü değiştirir. Terapistlerin ilişkiyle ilgili duruşunu belirleyen öğeler danışanın değişime ne kadar hazır olduğu, terapi tercihleri ve direnç düzeyidir. Lazarus'a göre (2013), örneğin çekingen olan ve gürültücü insanlardan rahatsız olan bir danışanla çalışırken fısıldar gibi konuşmak ve çok nazik olmak gerekir.

Davranışçı ve bilişsel-davranışçı terapilerin farklı formları danışanı anlama ve değerlendirmede biliş, duygulanım ve davranış olmak üzere üç boyutlu bir yaklaşım kullanırlar. Çok boyutlu terapide ise yedi boyutlu bir yaklaşım vardır. Duygulanım, davranış ve bilişin değerlendirilmesine ek olarak çok boyutlu terapide, duyusal tepkiler (sensory responses), zihinsel görüntüler / hayaller (mental images), kişiler arası faktörler (interpersonal factors) ve biyolojik durumlar da (biology) değerlendirilmektedir (Lazarus ve Abramovitz, 2004). Çok boyutlu değerlendirme şablonu BASIC ID kısaltmasıyla anı- 
lır. BASIC ID kısaltması bireyin kapsamlı davranışlarının İngilizce baş harflerinin birleştirilmesiyle oluşturulmuştur. Bunlar: "Behavior" (Davranış), "Affect" (Duygulanım), "Sensation" (Duyum), "Imagery" (İmgelem), "Cognition" (Biliş), "Interpersonal relationships" (İnsan ilişkileri) ve “Drugs / Biological factors" (İlaçlar / biyoloji) şeklindedir.

Çok boyutlu terapide kullanılacak olan süreçleri belirleyen en önemli faktör danışanın sorunlarıdır. Sorunların her biri BASIC ID alanlarında çok boyutlu bir değerlendirmeye tabi tutularak sinıflandırılır. Belli bir vakada benimsenen mekanizmalar seçilen tekniklere bağlıdır; tekniklerse danışanın sorunlarına göre seçilir. Danışanların yedi boyutlu davranışlarına şu teknikler kullanılarak müdahale edilir (Prochaska ve Norcross, 2014): Davranış: Olumlu ve olumsuz pekiştirme, karşıt koşullama, sönme, uyaran kontrolü; Duygulanım: Duyguları tanıma, kabul etme, netleştirme ve duygusal boşalma sağlama; Duyu: Gerilimi boşaltma; İmgelem: Başa çıkma imgeleri, kendilik imajını değiştirmek; Biliş: Bilişsel yeniden yapılandırma, farkındalı̆̆ı artırma, psiko-eğitim; İnsan ilişkileri: Sosyal becerilerin geliştirilmesi, sağlıksız ilişkilerin gözden geçirilmesi, yargılamadan kabullenmeyi öğrenme; İlaçlar / biyoloji: Tıbbi hastalıkların tespiti, madde bağımlılığının sona erdirilmesi, sağlıklı beslenme ve spor, gerekli görüldüğünde ilaç kullanımı.

Teknikleri ve ilişkisel duruşu her vakada kişiye ve ihtiyaca özel hale getirmek oldukça fazla enerji ve ustalık isteyen bir iş olsa da Lazarus psikoterapi sürecinin böyle olması gerektiğini, her danışan ve sorun için ayn tekniklerin işe yaramasının mümkün olmadığını; her danışana ve soruna aynı tekniklerle yaklaşmanın insanların kişilik çeşitliliği ve davranışların çok faktörlü oluşuyla çeliştiğini savunur.

\section{Kuramsal Bütünleşme}

Psikoterapide bütünleşme yollarından bir diğeri kuramsal bütünleşmedir. Kuramsal bütünleşme, bütünleşme tarzları arasında belki de en zor ve karmaşık olanıdır; çünkü farklı kuramsal yaklaşımlardan kavramları bir araya getirmeye çalışır. Paul L. Wachtel tarafından 1977 yılında yazılan Psikanaliz ve Davranış Terapisi: Bütünleşmeye Doğru adlı eserin kuramsal bütünleşme çağını açtı̆̆ına inanılır ve eserin kuramsal bütünleşme yönündeki girişimlerin başlangıcı olduğu kabul edilir. Wachtel psikanaliz ve davranışçı kuramı bü- 
tüncül psikodinamik davranış terapisi adı altında kuramsal olarak bütünleştirmeye çalışmıştır. Wachtel'e göre psikanaliz erken dönem deneyimlerinin nedensel rolünü aşırı vurguluyor ve değişim için içgörünün rolünü fazlaca önemsiyordu ancak sönme süreci ve sosyal becerilerin rolü yetersiz görülüyordu. Bunun yanında davranış terapisi aktif müdahale olanağı sunuyor; davranışın bağlamsal açıdan ele alınması gerektiğine dikkat çekiyordu (Prochaska ve Norcross, 2014). Bu nedenle Wachtel psikodinamik kavramlara bağlılığını hep sürdürmüş olsa da davranışçı ögeleri de terapi anlayışına dahil etmeyi gerekli gördü.

Bu bütüncül psikoterapide, «psikanalitik» irdeleme yapılarak danışanın içgörü kazanması sağlanırken; diğer yandan da davranışçı yaklaşımın aktif ve eylem odaklı oluşu kullanılır. Atılganlık eğitimi ve sistematik duyarsızlaştırma gibi yaklaşımlarla danışanın döngülerini kırması sağlanmaya çalışılır. Döngüsel psikodinamik terapiye göre insanlar yeni ilişkiler kurmak isteseler de bu ilişkilerde farkında olmadan çocukluk deneyimlerinin tekrarını yaşarlar. Çünkü çocukluk deneyimleri daha iyi ve olgun seçimler yapma yeteneklerini sınırlar. Bireyler vaktiyle elde edemedikleri mutluluğu elde edebilmek için bilinçsizce geçmişi yeniden yaratmaya çalışırlar. Döngüsel psikodinamik terapide amaç danışanların eski çerçevelerinden çıkmalarını, geçmişi ironik bir şekilde tekrar etmeyi azaltmalarını sağlamaktır. Psikoterapide danışanlar kişiler arası ilişkilerde yeni deneyimler kazanarak, eski deneyimlerin yeni deneyimleri olumsuz bir şekilde etkilemesinin önüne geçme konusunda daha uyanık hale gelirler (Gold ve Wachtel, 2012).

En yaygin ve kabul gören bütünleşme yaklaşımlarından bir diğeri de Proshaska ve DiClemente'nin kuramlar ötesi psikoterapi yaklaşımıdır. Bu yaklaşımda terapist, danışanınla ilgili üç konuyu netleştirdikten sonra müdahale tekniklerini seçer. Bunlar gerekli ortak terapötik faktörler veya değişim mekanizmaları, danışanın yardım aradığı konularda bulunduğu aşama ve gerekli değişim düzeyidir (Gold, 2002). Prochaska ve DiClemente (2014) bütün psikoterapilerde ortak olarak çalışan 10 olası değişim faktöründen söz ederler: Bunlar, bilinci artırmak, kendini özgürleştirme, sosyal özgürlük, karşıt koşullama, uyarıcı kontrolü, kendini yeniden değerlendirme, beklenmedik olayların yönetilmesi, dramatik rahatlama ve ilişkiye yardımdır. Pek çok terapi modeli bu müdahalelerin sadece 2 ya da 3 'ünü içermektedir. Kuramlar ötesi terapist istenen değişim düzeyi için en iyi etkiyi gösterecek, danışanın 
değişim için hazırlık düzeyine uygun ve en güçlü değişim faktörlerine maruz bırakacak müdahaleleri seçer.

Kuramsal bütünleşmenin diğer bir önemli örneği Antony Ryle'ın (1990) bilişsel analitik terapisidir. Bilişsel analitik terapi psikanalitik, bilişsel ve yap1landırmacı yaklaşımların kuram ve uygulamalarının bütünleştirilmesiyle oluşmuştur. Bilişsel analitik terapi, psikoterapi sonuç araştırmalarından etkilenerek ve etkili zaman sınırl yöntemlere duyulan ihtiyaçtan doğmuş bir yaklaşımdır (Ryle, 2005; Ryle ve Kerr, 2008). Ryle, kendiliğin ve diğerlerinin bilinçdışı imgelerinin bilişsel olarak yeniden kavramsallaştırılabileceğini düşünmüştür. Bu kuramsal bütünleşme bilişsel analitik terapiste, danışanın davranışlarını olumsuz anlamda güçlü bir şekilde etkileyen ama farkında olmadığı bu kendilik ve diğerleri tanımlarının bilişsel tekniklerle aktif olarak yeniden biçimlendirilmesi olanağını sağlar (Gold, 2002).

Üçüncü kuşak bilişsel davranış̧̧ı terapilerin de kuramsal bütünleşme kapsamına girdiği iddia edilebilir (Norcross, 2015). Üçüncü kuşak terapilerde tüm içsel deneyimlerin kabulü, içgörü, anın tam olarak farkında olma (mindfullness), duygular ve duygu düzenlemenin önemi klasik bilişsel davranışçı yaklaşımlara eklenerek, bilişsel-davranış̧ı kuramın kapsamı genişletilmiştir. $\mathrm{Bu}$ kuşakta içsel deneyime dair farkındalık ve içsel duyumları değiştirmek yerine kabul sürecinin altı çizilmektedir. İkinci kuşakta düşünceler ve düşüncelerin değiştirilmesi terapinin odağındayken, üçüncü kuşakta davranışlar, düşünceler, duygular, üst-bilişsel süreçler ve duygulara ilişkin öz-değerlendirmeler bütüncül bir şekilde ele alınmaktadır. Üçüncü kuşak yaklaşımlarla birlikte bilişsel davranış̧̧ı anlayış duygulara da yakınlaşmış durumdadır.

\section{Ortak Faktörler}

Ortak faktörler yaklaşımı, farklı terapilerin paylaştığı temel bileşenleri belirlemeyi ve ortaklıklarına dayanarak daha etkili terapiler yaratmayı hedeflemektedir. Hubble, Duncan ve Miller (1999), The Heart and Soul of Change (Değişimin Kalbi ve Ruhu) (1991) adlı kitaplarında bireysel terapi, farmakoterapi, aile terapisi ve eğitimle olsun, davranış değişikliği yaratmada ortak etkenlerin rolünün önemini vurgulayarak psikoterapide ortak etkenleri savunan önemli isimler olmuşlardır. Bu ortak etkenler danışanla, ilişkiyle, umut ve beklenti düzeyi ve kullanılan model ve tekniklerle ilgili etkenlerdir. Danı- 
şan / Ekstraterapötik Etkenlerle danışanların kendisi ve yaşamlarındaki birtakım etkenler kastedilmektedir. Danışanın terapiye beraberinde getirdiği bu kişisel ve çevresel etmenler destekleyici aile üyeleri, şans olayları, manevi eği$\mathrm{lim}$, azim, başa çıma becerileri ve ego gücüdür. Örneğin aile çatışmaları ve aileden alınan desteğin düşük olması terapi sonucunu olumsuz etkiler (Beitman, Soth ve Bumby, 2005). İlişki ise danışan ve danışman arasındaki içten, sıcak, cesaretlendirici ve empatik ilişkiyi ifade etmektedir. Danışanın terapötik sürece olan güveni, iyi geleceğine ilişkin umudu ve olumlu beklentisi üçüncü büyük ortak etmen olan plasebo, umut ve beklentidir. Kullanılan model ve tekniklerin psikoterapinin sonucuna etkisinin ise, danışanla ilgili ve ilişki faktörlerden daha az bir orana sahip olduğu düşünülmektedir.

Ortak faktörler yaklaşımına yöneltilen eleştirilerden biri, bütünleştirme sadece ortak faktörlere dayandırıldığında gelişmiş kuram ve tekniklerin zengin içeriğinin kaybedileceği yönündedir. Ne var ki, terapi sürecinde bir yandan ortak faktörlerden yararlanırken diğer yandan da terapiste ve danışana uygun teknik ve stratejilerden faydalanmamak için hiçbir neden yoktur (Evans ve Gilbert, 2012). Varolan kuram ve teknikler varlığını ve gelişimini devam ettirirken dahi danışanlara iyi gelen ortak terapötik faktörlerin belirlenmesi her halükarda bir kazanç olacaktır.

\section{Özümseyici Bütünleşme}

Bütünleşme yollarından bir diğeri olan özümseyici bütünleşme (Messer, 2015), bir kuramın merkeze alınması ancak diğer kuramların tekniklerinin de özümsenmesiyle oluşur. Özümseyici bütünleşme yaklaşımında, merkezde bir temel kuram bulunurken, diğer yaklaşımların teknik ve kavramları bu orijinal yönelime asimile edilir (Özakkaş, 2018). Özümseyici bütünleşme kuramsal bütünleşme ve teknik eklektisizmden türemiştir. Temelde ana bir kuram vardır ancak ihtiyaç duyulduğunda diğer yaklaşımların tekniklerinden de faydalanılabilir. Örneğin psikodinamik kuram yönelimli bir terapist, davranış̧̧ı tekniklerden sistematik duyarsızlaşmayı kullanabilir. Psikoterapide özümseyici bütünleşme yaklaşımı, diğer sistemlerden uygulamalan ve görüşleri seçici bir şekilde dahil ederek kendini bir sistemde toparlamaktır. Eşmerkezli bütünleşmeciler, çekirdekleri olarak tek bir tutarlı kuramsal sistemi kullanırlar ancak farklı sistemlerden gelen çok çeşitli teknik müdahaleleri ödünç alırlar. 
Özümseyici bütünleşmenin tipik bir örneği Stricker ve Gold'un (2012) özümseyici psikodinamik bütüncül terapisidir. Bu yaklaşımda, terapist psikodinamik kuram rehberliğinde ilerler ama gerektiğinde diğer terapi yöntemlerinden yararlanır. Özümseyici bütüncül psikoterapi danışanı anlamak için psikodinamik formülasyonu kullanır; teknik seçimi de psikodinamik müdahalelerden oluşur ancak bilişsel, davranış̧̧ı ve hümanist yaklaşımlardan da teknikler kullanılır. Stricker ve Gold (2005), psikodinamik ekole göre yetişmiş ve kendilerini psikodinmik oryantasyonlu olarak tanımlayan terapistlerdir. Ancak farklı ekollerden meslektaşlarından çok şey öğrendiklerini ve farklı terapi okullarının kavram ve tekniklerinden yararlanarak psikodinamik görüş ve yöntemlerin güçlendirilebileceğini fark ettiklerini ifade etmektedirler. Özümseyici psikodinamik bütüncül terapide kuramın merkezine psikodinamik görüş alınmaktadır. Bu görüşe göre acı veren anılarımız ve deneyimlerimiz ile kim olduğumuz, anne babamız ve sevenlerimiz için kim olduğumuz ve anne-babalarımızın ve diğer sevdiklerimizin kim olduklarına ilişkin çatışmalı düşünceler bilinçdışına atılmaktadır. Kendilerini bütüncül terapistler olarak tanımlayan Stricker ve Gold (2005), bilinçdışını dikkate almakla birlikte bilinç ve bilincin unsurları olan duygu, düşünce, algı ve ve davranışın kişilikte ve psikopatolojide önemli rol oynadıklarını ve sıklıkla doğrudan müdahale edilmeyi gerektirdiklerini düşünmektedirler.

Bilişsel-davranışcı özümseyici bütünleşme de bu kuşağın bir diğer temsilcisidir. Bilişsel davranışçı özümseyici terapide temele bilişsel-davranışçı yaklaşım alınırken, yaklaşım kişiler arası ve duygusal boyutlar açısından zenginleştirilerek kuramın boyutları genişletilmiştir (Castonguay, Newman, Borkovec, Holtforth ve Maramba, 2005). Bütüncül felsefenin etkisiyle ve kişilik bozukluklarına odaklanan bir yaklaşımla Jeffrey Young tarafından geliştirilen şema terapi de yine bu bütünleşme tarzı kapsamında düşünülebilir. Şema terapi geleneksel bilişsel-davranışçı terapiler ve kavramlar üzerine kurulu bir terapi olmakla birlikte bilişsel, davranışçı, bağlanma, gestalt, nesne ilişkileri, yapılandırmacı ve psikanalitik ögeleri harmanlamaktadır (Costunguay vd., 2015). Şema terapisti danışanının öncelikle şemalarının dinamik kökenlerini anlamasını sağlamaya çalışmakta, ardından şemaları fark etmesini ve onlarla savaşmasını teşvik etmektedir. Ardından terapide duygusal / yaşantısal aşamaya gelinmekte ve danışanın duygularıyla ve olumsuz çocukluk anılarıyla yaşantısal tekniklerle çalışılmaktadır. Terapinin sonraki aşamasında ise danışanın eyleme geçmesi sağlanarak, işlevsel olmayan davranışların azaltılması 
ve sağlıklı yetişkin davranışlarının uygulanmaya başlanması için davranışçı teknikler kullanılır (Young, 2009). Dolayısıyla şema terapinin özümseyici bütüncül bir yaklaşım olduğu söylenebilir. Diğer yandan şema terapi kendine özgü yeni kavram ve yaklaşımlar da barındırmaktadır. Şema terapinin, bütünleşmenin esas alındığı bir organizasyon içinde yeni ve özgün yapılar barındırmanın da mümkün olduğunu göstermesi açısından önemli olduğu düşünülmektedir.

Son zamanlarda nörobiyolojik çalışmalar sonucunda duygu şemalarının önemi keşfedilmiş ve psikoterapide duygularla çalışmanın, terapide değişimin gerçekleşmesi için son derece önemli olduğu noktasına gelinmiştir. Bu kapsamda duygu odaklı terapi günümüzde önemli bütüncül terapi modellerinden biridir. Duygu odaklı terapi de, hümanist-fenomenolojik terapi kuramları, duygu ve biliş kuramı, duygulanım nörobilimi, dinamik kuram ve aile sistemleri kuramların birleştiren bütüncül bir kuramdır (Greenberg, 2012).

\section{Sonuç}

Genel anlamda psikoterapide bütünleşme, insanların neden ve nasıl değiştiğini anlamak ve onlara daha iyi yardım edebilmek için belirli bir yaklaşım ya da kurama bağlı kalmaktan ziyade diğer yaklaşımları keşfetmeye ve onlara karşı açık olmaya teşvik eden bir anlayıştır (Arkowitz, 1991). Psikolojide farklı kuramlar ortak bir dil oluşturma gayretiyle ve hedefiyle incelendiğinde benzer davranış, durum ve olgular için farklı terimler kullanıldığı görülür. Örneğin insanların hayatlarındaki tekrarlayıcı yıkıcı örüntüleri ifade etmek için kullanılan kısır döngünün psikanalizdeki karşılığ1 "nevrotik tekrarlama zorlantısı", transaksiyonel analizdeki karşılığı "oyun", gestalt psikolojisindeki karşıllı̆̆ "değişmez gestalt" ve bilişsel terapideki karşıllğının "temel şema" olduğu söylenebilir. Kuramclar kendi terapötik dillerine o kadar gömülmüşlerdir ki, başka bir dilden konuşanların da aslında aynı şeyden bahsettiklerini fark etmeyebilirler (Evans ve Gilbert, 2012). Ancak dikkatli bir gözden geçirme ve değerlendirme farklı görünen pek çok kavramın daha önce dile getirilmiş bir olgunun yeni adlandırması olduğunu ortaya koyar. Dolayısıyla farklı gibi görünen kuramlar arasındaki benzerlikleri bulmak ve ortak bir dil oluşturmak insanı tanıma ve anlama yolculuğunda alınan yolu netleştirmek adına önemli görünmektedir. Günümüzde pek çok kuramsal 
yaklaşımın bütüncül bir yapıda olması bütünleşmenin doğru ve güçlü bir hareket olduğunu gösterir niteliktedir.

Diğer yandan bütünleşme çabaları içinde dahi bütünleşmenin nasıl olması gerektiğine ilişkin bölünmeler olduğu görülmektedir. Kegan'ın (1998) belirttiği gibi bütünleşme farklılıklar içinde benzer olanı arama arayışıdır. Bazı bilim insanları bütünleşme hareketinin kendi içinde de yeni bölünmeler olmaması gerektiğine dile getirmektedir. Örneğin Stricker ve Gold (2012) bütüncül terapilerin çoğalması ve popülerleşmesiyle ilgili olarak ironik ve istenmeyen bir problemin doğabileceğine dikkat çekmektedirler. Yazarlara göre bu problem aslında psikoterapide bütünleşme hareketinin çözmeye çalıştığ 1 bir problemdir. Bütüncül psikoterapistlerin yeni psikoterapi formları yaratma konusunda en az bütüncül olmayan meslektaşları kadar becerikli oldukları görülmektedir. Stricker' ın (1994) ifade ettiği gibi "Psikoterapi entegrasyonu bir ürüne değil, sürece tekabül eder." Dolayısıyla bütünleşmeye davet eden bir anlayışın yeni kuramsal yaklaşımlar ortaya koymaktan ziyade bütünleşme anlayışın yayması ve ortaklıklara odaklanması gerekmektedir.

Diğer yandan psikoterapi araştırmalarının sonuç araştırmalarındansa süreci inceleyen araştırmalara odaklanması gerektiği dile getirilmektedir. Örneğin Ahn ve Wampold (2001) yaptıkları meta-analiz çalışmalarının sonuçlarına dayanarak psikoterapi sonuç araştırmalarının anlamlı farklılıklara işaret etmediğini belirtmektedirler. Bu nedenle psikolojik danışma ve psikoterapide sonuç araştırmalarındansa süreç ve ortak faktörlere odaklanan araştırmalara ihtiyaç olduğunu vurgulamaktadırlar. Norcross ve Beutler (2013)'e göre psikoterapiler bundan sonra kuramsal yönelimleri ve marka isimleriyle değil, etkililik ve uygulanabilirliklerine göre tanımlanacaklardır. Bir kuramın neredeyse her türlü ruhsal sorunda işe yaradığını kanıtlamaya çalışan sonuç araştırmaları yerine süreç araştırmalarına odaklanılması, ilgili terapinin hangi yaş gruplarında, hangi sorun alanlarında, hangi kişilik özelliklerine sahip danışanlarda ve hangi bağlamlarda daha etkili olduğunun belirlenmesini sağlayacaktır.

Günümüzde bütünleşme çabaları devam etmekle birlikte hala alınacak önemli yollar vardır. Norcross'a (2015) göre bütünleşme için çabalayanlar, zamanla bütünleşme sürecinin zorlukları ve olumlu sonuçlarıyla daha da fazla karşılaşacaklardır. Bunlar; tarihinde benzeri görülmemiş bir görev olarak çoklu kuramsal bakış açısına sahip öğrencilerin yetiştirilmesi için eğitim programları düzenlenmesi; farklı psikoterapi kuramlarının somutlaştırdığı, 
bütünleşmeyi engelleyen altta yatan ontolojik ve epistemolojik farklılıkları kabul etmek ve farklı jargonları anlamada kafa karışıklığı yaratan dil sorununu ele almaktır. Bütünleşmeye inanan bilim insanlarını bekleyen önemli işler ve görevler olduğu görülmektedir.

İşi insanı anlamak ve ruhsal sorunlarının çözümünde yardımcı olmaya çalışmak olan ruh sağlığı uzmanlarının, insan davranışlarını benzer yollarla anlayıp kavramsallaştırmaları psikoloji biliminin tutarlılık ve güven sunması açısından önemli görülmektedir. İnsan davranışlarını ve terapisini açıklamada ortak bir dil geliştirme gayreti değerlidir. Elbette var olan bilimsel bilgiler zaman içinde sınanmaya devam edecektir ancak psikoloji ve psikoterapi kuramlarını sürekli farklı ve yeni kuram iddialarıla türemeye devam etmesi hem alandaki uzmanları zorlamakta hem de danışanların sorunlarının kavramsallaştırılmasını karmaşıklaştırmaktadır. Bu nedenle bütünleşme çabaları önemlidir ve devam etmelidir.

Terapistlerin akademik birikimlerini, kendi kişilik yapılarını, güçlü ve zayıf yanların, değerlerini ve deneyimlerini düşünerek kendi bütüncül tarzlarını yaratmaları mümkündür. Tek bir kuramın insanı her yönüyle açıkladığını savunmak dogmatik bir anlayış olmaktadır. Terapistler belli bir kuramı merkeze alabilirler ancak diğer kuramsal anlayışlara da açık olabilmelidirler. Corey (2015) psikolojik danışmanlara, kişilik yapılarını ve danışanlarının ihtiyaç duydukları yardım alanlarını düşünerek kendi bütüncül tarzlarını oluşturmalarını önermektedir. Psikolojik danışmanlar, temel psikolojik danışma kuramlarını tanıyarak, kendi kişiliklerine uygun bir tarz geliştirebilirler. Psikolojik danışma ve psikoterapi kuramlarını bütünleştirme çabaları hakkında bilgi sahibi olmaları, kendi tarzlarını oluşturma yolculuğunda psikolojik danışmanlara ve psikoterapistlere rehber olacaktır. Psikolojik danışmanlar ve psikoterapistler bu kapsamda, Psikoterapide Bütünleşme Araştırmaları Derneği'nin (Society for the Exploration of Psychotherapy Integration, SEPI) çalışmalarını ve derneğin yayını olan Psikoterapide Bütünleşme Dergisi'ni (Journal of Psychotherapy Integration) takip edebilirler.

\section{Teşekkür}

Psikoterapide bütünleşme hareketi ve anlayışılla tanışmamı sağlayan değerli hocam Uzm. Dr. Tahir Özakkaş'a şükranlarımı sunarım. 


\title{
EXTENDED ABSTRACT
}

\section{Towards Integration in Psychological Counseling and Psychotherapy}

Meliha Tuzgöl Dost

Hacettepe University

\begin{abstract}
"Integration is not to form a mechanical combination of differences in methods but to look for what is similar within difference"

V. E. Kegan
\end{abstract}

This study focused on the inception, development, and present state of the integration movement in the field of psychotherapy and psychological counseling. To this end, books, book chapters, and research articles of prominent scientists in the field were examined to prepare a survey that could provide a general frame about the integration attempts.

There have been people who took it upon themselves to alleviate mental problems in every society; however, psychotherapists coming to the scene goes back approximately a hundred years (Stricker and Gold, 2012). There has not been one, single, universally accepted definition for psychotherapy. Nevertheless, any activity which gets to be called psychotherapy must be carried out with the sole purpose of "helping people" within the reciprocally accepted goals (Prochaska and Norcross, 2014). According to Norcross and Goldfried (2005), from the day Freud started using speech therapy to today, psychotherapy has been a world of division and dogmatism. After Freud's psychoanalysis comes behaviourism, cognitive approach, and humanist approaches. Today one can think of hundreds of approaches of psychotherapy. Indeed, the number of psychotherapy models and approaches increase with each passing day. Whether each of these approaches has different discourses and whether they offer completely different explanations to human behaviour and behaviour change are questions asked by those who believe in the 
need for integration for psychotherapies. Although there are numerous psychotherapy theories, recently there have been attempts to see commonalities between different movements.

These attempts are based on the following developments: Controlled results studies interestingly show that there is rather little difference between different psychotherapy applications. Examining meta-analysis studies where active therapies are compared also show little or insignificant difference (Luborsky et al., 2002). These developments have fuelled the attempts to seek similarities between different psychotherapy schools. There is no consensus as to how the integration should take place. There are difference approaches and ways to that. The integration process has been shaped after going through certain phases. According to Goldfried (1995a), the history of integration dates to the study carried out by French in 1932. Another important study is Dollard and Miller's book titled Personality and Psychotherapy (1950), which intended to build a bridge between psychoanalysis and behaviourism. This was followed by Paul Wachtel's Psychoanalysis and Behaviour Therapy: Towards an Integration (1977), which is a milestone. Then, in 1979, James Prochaska suggested an approach for psychotherapy beyond theories, which would be the first attempt to create a comprehensive theoretical frame; in the same year Marvin Goldfried, Paul Wachtel, and Hans Strupp founded the Society for the Exploration of Psychotherapy Integration (SEPI) for clinicians and academics interested in integration in psychotherapy (Prochaska and Norcross, 2014). Integration attempts have continued with the contribution of different theoreticians and clinicians.

There are several reasons for the increase in the integration studies in recent years. Norcross (2005) contends that there are mainly eight reasons for this increase. These are: 1 . Rise in therapies; 2 . Approaching every single client and their problems with a single theory falls short; 3 . External socio-economic conditions; 4. Rise in short-term, solution-focused therapies; 5. Possibilities for therapist to observe various treatments especially for difficult problems; 6 . The realisation that therapeutic common factors have significant contributions to the result of the therapy; 7 . The effect of certain therapies to have been defined and proof-based therapies; and 8. Development of an integration-focused professional organisation.

There are several ways to psychotherapies to be integrated. The primary models of integration are 1. Technical eclecticism, 2. Theoretical integration, 
3. Common factors, and 4. Assimilative integration (Norcross and Goldfried, 2005). Technical eclecticism includes using the techniques of different approaches without trying to create a new conceptual model that combines different theories. Theoretical integration denotes integrating two or more psychotherapy theories or techniques to create a new conceptualisation or a new therapy approach. Common factors approach focuses on shared components and principles between different therapeutic orientations by moving beyond the claim that theories are unique. Finally, different from all these three, assimilative integration prefers to stick to a fundamental theoretical orientation while integrating the techniques and principles of other orientations (Castonguay et al., 2014, p. 4).

Generally speaking, integration in psychotherapy is a perspective that encourages to be open about other approaches and explore them without adhering to a certain approach or theory in order to help people better and to understand why and how they change (Arkowitz, 1991). Examining different theories in an attempt to create a common language shows that different terms have been in use for similar behaviours, situations, and phenomena. In this respect, finding similarities between seemingly disparate theories and creating a common language is important to provide clarity for the journey of knowing and understanding the humankind. The holistic structure of many of the theoretical approaches today indeed proves how right and strong a movement integration is. It is important that experts of mental health to understand human behaviour and conceptualise it in similar ways so that psychology as a science is consistent and trustworthy. That is why these attempts to formulate a common language in explaining human behaviours and therapy are highly valuable.

It is possible for therapists to create their own holistic styles keeping in mind their academic knowledge, their personalities, strong and weak features, values, and experiences. Claiming that one single theory can explain every aspect of the human being is dogmatic. Therapists may focus on a certain theory, but they should be open to other theoretical approaches. Corey (2015) suggests that psychological counselors should create their own holistic styles by considering their own personalities along with the fields their clients need help. Psychological counsellors can develop a style that would fit their personalities by knowing basic theories in psychological counseling. Having knowledge about the integration attempts in psychological counseling and 
psychotherapy theories would guide psychological counselors and therapists in their journey to create their own styles. Psychological counselors and psychotherapists can follow, in this respect, the works of Society for the Exploration of Psychotherapy Integration (SEPI) and Journal of Psychotherapy Integration, its publication.

\section{Kaynakça / References}

Ahn, H. ve Wampold, B. E. (2001). Where oh where are the specific ingredients? A meta-analysis of component studies in counseling and psychotherapy. Journal of Counseling Psychology, 48(3), 251-257. https://doi.org/10.1037/0022-0167.48.3.251

Arkowitz, H. (1991). Introductory statement: Psychotherapy integration comes of age. Journal of Psychotherapy Integration, 1(1), 1. https://doi.org/10.1037/h0101205

Beitman, B. D., Soth, A. M. ve Bumby, N. A. (2005). The Future as an integrating force through the schools of psychotherapy. Norcross, J. C. ve Goldfried, M. R. (Der). Handbook of psychotherapy integration içinde (2.bsm., s. 6583). New York: Oxford University Press.

Corey, G. (2015). Psikolojik danışma, psikoterapi kuram ve uygulamaları. Ankara: Mentis Yayıncilik.

Castonguay, L. G., Eubanks, C. F., Goldfried, M. R., Muran, J. C., ve Lutz, W. (2015). Research on psychotherapy integration: Building on the past, looking to the future. Psychotherapy Research, 25(3), 365-382. https://doi.org/10.1080/10503307.2015.1014010

Castonguay, L. G., Newman, M. G., Borkovec, T. D., Holtforth, M. G. ve Maramba, G. G. (2005). Cognitive-behavioral assimilative integration. J. C. Norcross ve M. R. Goldfried (Der.), Handbook of psychotherapy integration içinde (2. bsm. 241-260). New York, NY: Oxford University Press. http://dx.doi.org/10.1093/med:psych/9780195165791.003.0011

Dollard ve Miller, N. E, (1950). Personality and psychotherapy. New York: McGrawHill.

Evans, K. R. ve Gilbert, M. C. (2012). Bütüncül psikoterapiye giriş. İzmit: Psikoterapi Enstitüsü Yayınları.

Fernández-Álvarez, H., Consoli, A. J., ve Gómez, B. (2016). Integration in psychotherapy: Reasons and challenges. American Psychologist, 71(8), 820-830. https://doi.org/10.1037/amp0000100 
Gold. J. (2002). Integrative approaches to psychotherapy. Encyclopedia Britannica (Cilt 2). Elsevier Science (USA), 25-35.

Gold, J. ve Stricker, G. (2012). Giriş: Psikoterapide Bütünleşmeye Genel Bakış. Stricker, G. ve Gold, J. (Der.) Psikoterapide Bütünleşme Vaka Kitabı içinde. İzmit: Psikoterapi Enstitüsü Yayınları.

Gold, J. ve Wachtel, P. L. (2012). Döngüsel psikodinamikler. Stricker, G. ve Gold, J. (Ed.) Psikoterapide Bütünleşme Vaka Kitabı. İzmit: Psikoterapi Enstitüsü Yayınları.

Goldfried, M. R. (1995a). Toward a common language for case formulation. Journal of Psychotherapy Integration, 5(3), 221244. https://doi.org/10.1037/h0101272

Goldfried, M. R. (1995b). From cognitive-behavior therapy to psychotherapy integration: An evolving View. New York: Springer Publishing Company.

Greenberg, L. S. (2012). Duygu odaklı terapi. (Çev. S. Kızıltaş) İzmit: Psikoterapi Enstitüsü Yayınları.

Hollanders, H. (2009). Eclecticism:Integration some key issues and research. Palmer, S. ve Woolfe, R. (Der.) Integrative and Eclectic Counseling and Psychotherapy içinde (ss. 31-56). London: SAGE Publications Inc.

Hubble, M. A., Duncan, B. L. ve Miller, S. D. (1999). Directing attention to what works. M. A. Hubble, B. L. Duncan ve S. D. Miller (Der.), The heart and soul of change: What works in therapy içinde (ss. 407-447). Washington, DC: American Psychological Association.

Kegan. V. E. (1998). Psychology and Psychotherapy: Humanization and Integration. Journal of Russian \& East European Psychology, 36(1), 5-17. Doi: doi.org/10.2753/RPO1061-040536015

Lazarus, A. A. (1973). Multimodal behavioral therapy: Treating the "basic id". The Journal of Nervous and Mental Disease, 156(6), 404-411. https://doi.org/10.1097/00005053-197306000-00005

Lazarus, A. A. (2013). Çok boyutlu terapi uygulaması: Sistematik kapsamlı ve etkili psikoterapi. İzmit: Psikoterapi Enstitüsü Yayınları.

Lazarus, A. A. ve Abramovitz, A. (2004). A multimodal behavioral approach to performans anxiety. Journal of Clinical Psychology, 60(8), 831-840.

https://doi.org/10.1002/jclp.20041

Luborsky, L., Singer, B. ve Luborsky, L. (1975). Comparative studies of psychotherapies: Is it true that "everybody has won and all must have prizes"? Archives of General Psychiatry, 32, 995-1008. doi:10.1001/archpsyc.1975.01760260059004 
Luborsky, L., Rosenthal, R. Diguer, L., Andrusyna, T. P., Berman, J. S., Levitt, J. T., Seligman, D. A. ve Krause, E. D. (2002). The Dodo bird verdict is alive and well-mostly. Clinical Psychology; Science and Practice, 9, 212. https://doi.org/10.1093/clipsy.9.1.2

Messer, S. B. (2015). How I changed over time as a psychotherapist. Journal of Clinical Psychology, 71(11), 1104-1114.

Murdock, N. L. (2012). Psikolojik danışma ve psikoterapi kuramları: Olgu sunumu yaklaşımıyla. (Çev. Ed. F. Akkoyun). Ankara: Nobel Yayınevi.

Norcross, J. C. (2005). Primer on psychotherapy integration. Norcross, J. C. ve Goldfried, M. R. (Der.). Handbook of Psychotherapy Integration içinde (2. bsm, s. 3-23). New York: Oxford University Press.

Norcross, J. C. (2013). Psychotherapy integration. International Encyclopedia of the Social \& Behavioral Sciences (2. bsm.), (Cilt. 19, s. 509-514). Doi: dx.doi.org/10.1016/B978-0-08-097086-8.21068-4

Norcross, J. C., ve Beutler, L. E., (2013). Evidence-based relationships and responsiveness for depression with substance abuse. Barlow, D.H. (EDer.), Clinical Handbook of Psychological Disorders, 5. bsm. Guilford, New York.

Norcross, J. C. ve Goldfried, M. R. (Der..) (1992). Handbook of psychotherapy integration. New York: Basic Books.

Norcross, J. C. ve Goldfried, M. R. (Der..). (2005). Handbook of psychotherapy integration. New York, NY: Oxford University Press.

Özakkaş, T. (2018) Psikoterapi tarihi ve bütüncül psikoterapi. Türkiye Bütüncül Psikoterapi Dergisi, 1(1), 1-24.

Prochaska, J. O. ve Diclemente, C. C. (2014). The transtheoretical approach. Norcross, J. C. ve Goldfried, M. R. (Der.). Handbook of psychotherapy integration içinde (2. bsm, s. 147-171). New York: Oxford University Press.

Prochaska, J. O. ve Norcross, J. C. (2014). Psikoterapi sistemleri: Teoriler ötesi bir çözümleme. İzmit: Psikoterapi Enstitüsü Yayınları.

Ryle, A. (1990). Cognitive analytic therapy: Active participation in change. Chichester, England: Wiley.

Ryle, A. (2005). Cognitive Analytic Therapy. Norcross, J. C. ve Goldfried, M. R. (Eds). Handbook of Psychotherapy Integration (2. bsm., s. 196-217). New York: Oxford University Press.

Ryle, A. ve Kerr, I. B. (2008). Introduction cognitive analytic therapy: Principles and practice. West Sussex, John Wiley \& Sons. Ltd.

Sharf, R. S. (2014). Psikoterapi ve psikolojik danışma kuramları: Kuramlar ve örnek olaylar (Çev. Ed. N. V. Acar). Ankara: Nobel Yayınevi. 
Stricker, G. (1994). Reflections on psychotherapy integration. Clinical Psychology: Science and Practice, 1(1), 3-12. https://doi.org/10.1111/j.14682850.1994.tb00002.x

Stricker, G. ve Gold, J. (Eds.) (1993). Comprehensive handbook of psychotherapy integration. New York: Plenum Press.

Stricker, G. ve Gold, J. (2005). Assimilative Psychodynamic Psychotherapy. Norcross, J. C. ve Goldfried, M. R. (Eds). Handbook of psychotherapy integration içinde (2. bsm, ss. 221-240). New York: Oxford University Press.

Stricker, G. ve Gold, J. (2012). Giriş: Psikoterapide bütünleşmeye genel bakış. Stricker, G. ve Gold, J. (Eds.) Psikoterapide bütünleşme vaka kitabı içinde (ss. 1-20). İzmit: Psikoterapi Enstitüsü Yayınları.

Tracy, A. P. (2018). Introduction to the special issue on psychotherapy integration. Journal of Infant, Child, and Adolescent Psychotherapy, 4, 229-231. https://doi.org/10.1080/15289168.2018.1527570

Wachtel, P. L. (1997). Psychoanalysis, behavior therapy, and the relational world. Washington, DC: American Psychological Association.

Wolfe, B. E. ve Goldfried, M. R. (1988). Research on psychotherapy integration: Recommendations and conclusions from an NIMH workshop. Journal of Consulting and Clinical Psychology, 56(3), 448-451. https://doi.org/10.1037/0022-006X.56.3.448

Young, J. E., Klosko, J. S. ve Weishaar, M. E. (2009). Şema terapi. İstanbul: Litera Yayıncilik.

\section{Kaynakça Bilgisi / Citation Information}

Tuzgöl Dost, M. (2020). Psikolojik danışma ve psikoterapide bütünleşmeye doğru. OPUS-Uluslararası Toplum Araştırmaları Dergisi, 15(10. Y1l Özel Say1s1), 5252-5276. DOI: 10.26466/opus.688166 